\title{
A new species of Micryletta Dubois, 1987 (Anura, Microhylidae) from Yunnan Province, China
}

\author{
Shuo Liư, Mian $\mathrm{Hou}^{2}$, Mingzhong $\mathrm{Mo}^{3}$, Dingqi Rao ${ }^{4}$ \\ 1 Kunming Natural History Museum of Zoology, Kunming Institute of Zoology, Chinese Academy of Sciences, 32 Jiaochang Donglu, Kunming, \\ Yunnan 650223, China \\ 2 College of Continuing (Online) Education, Sichuan Normal University, No. 5, Jing'an Road, Jinjiang District, Chengdu, Sichuan 610066, China \\ 3 Honghe Prefecture Forestry and Grassland Bureau of Yunnan Province, Honghe Avenue and Tianzhu Road's intersection, Mengzi, Yunnan \\ 661199, China \\ 4 Kunming Institute of Zoology, Chinese Academy of Sciences, No. 17 Longxin Road, Kunming, Yunnan 650201, China \\ http://zoobank.org/0B4CCOBB-19C0-4E1E-8542-E2CD5A9D6B60 \\ Corresponding authors: Shuo Liu (liushuo@mail.kiz.ac.cn); Dingqi Rao (raodq@mail.kiz.ac.cn)
}

Academic editor: Günter Gollmann • Received 5 June 2021 • Accepted 8 July 2021 • Published 23 July 2021

\begin{abstract}
A new species of the genus Micryletta Dubois, 1987 is described from Yunnan Province, China, based on morphological and molecular analyses. The most obvious differences between the new species and other species of this genus are small body size, unique coloration, and relatively longer hind limbs. In 16S rRNA gene sequences, the new species is diverged from all other congeners by $3.1 \%-8.0 \%$.
\end{abstract}

\section{Key Words}

16S rRNA, Hekou County, Honghe Prefecture, Paddy Frog, taxonomy

\section{Introduction}

The genus Micryletta was originally described by Dubois (1987). Initially, Micryletta was considered to be synonymous with Microhyla (Zhao and Adler 1993; Fei 1999), and eventually, it was shown to be phylogenetically distinct in the subfamily Microhylinae (Frost et al. 2006; Van der Meijden et al. 2007; Kurabayashi et al. 2011; Pyron and Wiens 2011; De Sá et al. 2012; Blackburn et al. 2013; Peloso et al. 2016; Tu et al. 2018; Poyarkov et al. 2018; Garg and Biju 2019).

To date, the genus Micryletta comprises nine recognized species: M. aishani Das, Garg, Hamidy, Smith \& Biju, 2019; M. dissimulans Suwannapoom, Nguyen, Pawangkhanant, Gorin, Chomdej, Che \& Poyarkov,
2020; M. erythropoda (Tarkhnishvili, 1994); M. immaculata Yang \& Poyarkov, 2021; M. inornata (Boulenger, 1890); M. lineata (Taylor, 1962); M. nigromaculata Poyarkov, Nguyen, Duong, Gorin \& Yang, 2018; $M$. steinegeri (Boulenger, 1909); and M. sumatrana Munir, Hamidy, Matsui, Kusrini \& Nishikawa, 2020. Among them, $M$. lineata had been regarded as a subspecies of $M$. inornata until it was recently elevated to full species (Zug and Mulcahy 2020; Miller et al. 2021).

During our fieldwork in Honghe Prefecture, Yunnan Province, China, in May 2021, two specimens of the genus Micryletta were collected from Hekou County. Phylogenetic analysis based on the 16S rRNA mtDNA gene showed the two specimens distinct from all other species of the genus. Thus, we describe these two specimens as a new species. 


\section{Materials and methods}

Field survey in Hekou County, Honghe Prefecture, Yunnan Province, China (Figure 1), was carried out under the permission of Daweishan National Natural Reserve Management and Protection Bureau. Specimens were fixed and preserved in $75 \%$ ethanol and deposited at Kunming Natural History Museum of Zoology, Kunming Institute of Zoology, Chinese Academy of Sciences (KIZ). Measurements were taken to the nearest $0.1 \mathrm{~mm}$ with digital calipers. Paired measurements were made on the left side. The descriptions of morphological characteristics followed Poyarkov et al. (2018) with minor modifications. SVL: snout-vent length, measured from the tip of the snout to cloaca; HL: head length, measured from the tip of snout to hind border of jaw angle; SL: snout length, measured from the anterior corner of eye to the tip of snout; EL: eye length, measured as the distance between anterior and posterior corners of the eye; NEL: nostrileye length, measured as the distance between the anterior corner of the eye and the nostril center; HW: head width, measured as the maximum width of head on the level of mouth angles in ventral view; IND: internarial distance, measured as the distance between the central points of nostrils; IOD: interorbital distance, measured as the shortest distance between the medial edges of eyeballs in dorsal view; UEW: upper eyelid width, measured as the maximum distance between the medial edge of eyeball and the lateral edge of upper eyelid; TMP: Tympanum length, measured as the horizontal tympanum diameter; FLL: forelimb length, measured as the length of straightened forelimb to the tip of third finger; LAL: lower arm and hand length, measured as the distance between elbow and the tip of third finger; HAL: hand length, measured as the distance between the proximal end of outer palmar (metacarpal) tubercle and the tip of third finger; 1FL: first finger length, measured as the distance between the tip and the distal end of inner palmar tubercle; IPTL: inner palmar tubercle length, measured as the maximum distance between proximal and distal ends of inner palmar tubercle; OPTL: outer palmar tubercle length, measured as the maximum diameter of outer palmar tubercle; 3FDD: third finger disk diameter; HLL: hindlimb length, measured as the length of straightened hindlimb from groin to the tip of fourth toe; TL: tibia length, measured as the distance between the knee and tibiotarsal articulation; FL: foot length, measured as the distance between the base of the inner metatarsal tubercle to the tip of the fourth toe; IMTL: inner metatarsal tubercle length, measured as the maximum length of inner metatarsal tubercle; 1TOEL: first toe length, measured as the distance between the distal end of inner metatarsal tubercle and the tip of first toe; 4TDD: fourth toe disk diameter. We compared morphological characters of the new species with other members of the genus relying on original species descriptions (Boulenger 1890, 1909; Taylor 1962; Tarkhnishvili 1994; Poyarkov et al. 2018; Das et al. 2019; Munir et al. 2020; Suwannapoom et al. 2020; Yang and

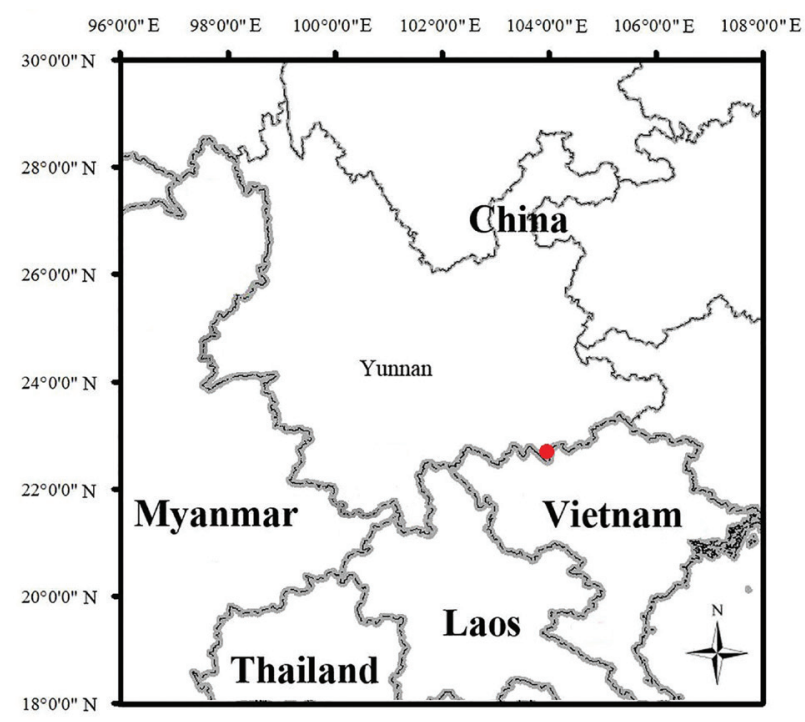

Figure 1. Map showing the type locality (red dot) of Micryletta hekouensis sp. nov.

Poyarkov 2021) and the additional data from Yang and Poyarkov (2021).

Total genomic DNA was extracted from liver tissues using the standard phenol-chloroform method (Hillis et al. 1996; Sambrook and Russell 2001). A fragment encoding mitochondrial 16S rRNA gene was amplified and sequenced. The primers L2188 (Matsui et al. 2006): 5'-AAAGTGGGCCTAAAAGCAGCCA-3' and 16H1 (Hedges 1994): 5'-CTCCGGTCTGAACTCAGATCACGTAGG-3' were used in amplification and cycle sequencing. Amplified DNA was produced in $20 \mu \mathrm{l}$ reactions after an initial denaturation step of $5 \mathrm{~min}$ at $94{ }^{\circ} \mathrm{C}$ and $43 \mathrm{cy}$ cles of denaturation for $1 \mathrm{~min}$ at $94{ }^{\circ} \mathrm{C}$, annealing for 1 min with the TouchDown program from $65{ }^{\circ} \mathrm{C}$ to $55^{\circ} \mathrm{C}$ reducing $1{ }^{\circ} \mathrm{C}$ every cycle, extension for $1 \mathrm{~min}$ at $72^{\circ} \mathrm{C}$, and final extension for $5 \mathrm{~min}$ at $72^{\circ} \mathrm{C}$. PCR products were isolated through electrophoresis using 1.5\% agarose gel, and further purified using Millipore Microcon Kits. Purified PCR products were sequenced by Davis Sequencing using BigDye terminator 3.1 and sequences were edited and manually managed using SeqMan in Lasergene 7.1 (DNASTAR Inc., Madison, WI, USA) and MEGA X (Kumar et al. 2018).

All new sequences have been deposited in GenBank, sequences of all eight nominal Micryletta taxa, including type specimens of $M$. aishani (India), M. dissimulans (Songkhla, Thailand), M. immaculata (Hainan, China), M. nigromaculata (Vietnam), and M. sumatrana (Sumatra, Indonesia), topotype specimens of M. inornata (Sumatra, Indonesia), M. erythropoda (Ma Da, Dong Nai, Vietnam), and $M$. steinegeri (Taiwan, China), as well as M. inornata sensu stricto from Tanintharyi, Myanmar, and $M$. lineata from southern Thailand and Myanmar (Poyarkov et al. 2018; Alhadi et al. 2019; Das et al. 2019; Munir et al. 2020; Suwannapoom et al. 2020; Miller et al. 2021; Yang and Poyarkov 2021) were downloaded from Genbank (Table 1). Sequences of Mysticellus fran- 
Table 1. Localities, voucher information, and GenBank accession numbers for all specimens used in molecular analyses in this study.

\begin{tabular}{|c|c|c|c|}
\hline Species & Voucher & Locality & Accession No. \\
\hline Micryletta aishani & SDBDU 3920 & India: Assam, Cachar district, Subhong & MK889218 \\
\hline Micryletta dissimulans & AUP01690 & Thailand: Songkla Prov., Saba Yoi district & MT573414 \\
\hline Micryletta dissimulans & AUP01691 & Thailand: Songkla Prov., Saba Yoi district & MT573415 \\
\hline Micryletta dissimulans & AUP01696 & Thailand: Songkla Prov., Saba Yoi district & MT573416 \\
\hline Micryletta dissimulans & AUP01698 & Thailand: Songkla Prov., Saba Yoi district & MT573413 \\
\hline Micryletta erythropoda & ZMMU A4721-1533 & Vietnam: Dong Nai, Ma Da (Vinh Cuu) N.R. & MH756146 \\
\hline Micryletta erythropoda & ZMMU A4721-1542 & Vietnam: Dong Nai, Ma Da (Vinh Cuu) N.R. & MH756147 \\
\hline Micryletta immaculata & KFBG 14270 & China: Hainan, Exian & MW376736 \\
\hline Micryletta immaculata & KFBG 14271 & China: Hainan, Exian & MW376737 \\
\hline Micryletta inornata & MZB Amph 23949 & Indonesia: Sumatra, Deli Serdang & LC208135 \\
\hline Micryletta inornata & MZB Amph 23947 & Indonesia: Sumatra, Deli Serdang & LC208136 \\
\hline Micryletta inornata & MZB Amph 23948 & Indonesia: Sumatra, Deli Serdang & LC208137 \\
\hline Micryletta inornata & MZB Amph 27242 & Indonesia: Sumatra, Aceh & LC208138 \\
\hline Micryletta inornata & USNM 587625 & Myanmar: Tanintharyi & MT609033 \\
\hline Micryletta inornata & USNM 587901 & Myanmar: Tanintharyi & MT609034 \\
\hline Micryletta lineata & KUHE 23858 & Thailand: Ranong & AB634695 \\
\hline Micryletta lineata & CAS 247206 & Myanmar: Tanintharyi Div., Kawthaung dist. & KM509167 \\
\hline Micryletta nigromaculata & ZMMU A5947 & Vietnam: Hai Phong, Cat Ba N.P. & MH756148 \\
\hline Micryletta nigromaculata & ZMMU A5937 & Vietnam: Hai Phong, Cat Ba N.P. & MH756149 \\
\hline Micryletta nigromaculata & ZMMU A5946 & Vietnam: Hai Phong, Cat Ba N.P. & MH756151 \\
\hline Micryletta nigromaculata & DTU 301 & Vietnam: Ninh Binh, Cuc Phuong N.P. & MH756154 \\
\hline Micryletta steinegeri & KUHE 35937 & China: Taiwan, Yunlin & AB634696 \\
\hline Micryletta steinegeri & ZMMU A5336-1 & China: Taiwan, Kaohsiung & MW376732 \\
\hline Micryletta steinegeri & ZMMU A5336-2 & China: Taiwan, Kaohsiung & MW376733 \\
\hline Micryletta steinegeri & ZMMU A5336-3 & China: Taiwan, Kaohsiung & MW376734 \\
\hline Micryletta sumatrana & 1 & Indonesia: Sumatra Selatan & MN727065 \\
\hline Micryletta hekouensis sp. nov. & KIZ20210510 & China: Honghe, Hekou & MZ536627 \\
\hline Micryletta hekouensis sp. nov. & KIZ20210511 & China: Honghe, Hekou & MZ536628 \\
\hline Mysticellus franki & ZSI/WGRC/V/A/967 & India: Kerala, Wayand & MK285340 \\
\hline Kaloula pulchra & NMNS 3208 & China & KC822614 \\
\hline Uperodon systoma & SDBDU 2005.4723 & India: Tamil Nadu: Kunnapattu & MG557949 \\
\hline
\end{tabular}

ki, Kaloula pulchra and Uperodon systoma were used as outgroups according to Suwannapoom et al. (2020) and Yang and Poyarkov (2021).

Sequences were aligned using ClustalW (Thompson et al. 1994) integrated in MEGA X (Kumar et al. 2018) with default parameters. Genetic divergences (uncorrected p-distance) were calculated in MEGA X with the parameters Transitions + Transversions, Uniform rates, and Pairwise deletion (Kumar et al. 2018). The best substitution model GTR+F+G4 was selected using the Akaike Information Criterion (AIC) in ModelFinder (Kalyaanamoorthy et al. 2017). Maximum likelihood phylogenetic analysis was performed in IQ-TREE 1.6.12 (Nguyen et al. 2015), and nodal support was estimated by 1,000 ultrafast bootstrap (UFB) replicates. Nodes with UFB values of 95 and above were considered significantly supported (Minh et al. 2013). Bayesian Inference was performed in MrBayes 3.2.7 (Ronquist et al. 2012) based on the selected substitution model. Two runs were performed simultaneously with four Markov chains starting from a random tree. The chains were run for 1,000,000 generations and sampled every 100 generations. The first $25 \%$ of the sampled trees were discarded as burn-in after the standard deviation of split frequencies of the two runs was less than a value of 0.01 , and then the remaining trees were used to create a $50 \%$ majority-rule consensus tree and to estimate Bayesian posterior probabilities (BPP). Nodes were considered well-supported if they had BPP of 0.95 or higher (Huelsenbeck et al. 2001; Wilcox et al. 2002).

\section{Results}

Bayesian inference and Maximum likelihood analyses recovered consistent topology (Figure 2) and agreed essentially with earlier phylogenies of Micryletta (Poyarkov et al. 2018; Das et al. 2019; Suwannapoom et al. 2020; Yang and Poyarkov 2021). The two specimens from Hekou County were nested in the genus Micryletta and formed a distinct clade sister to a clade consisting of $M$. immaculat $a$ and $M$. steinegeri with strong support.

The genetic divergences between the two specimens from Hekou County and all other congeners ranged from $3.1 \%$ (with $M$. steinegeri) to $8.0 \%$ (with $M$. nigromaculata) (Table 2).

\section{Micryletta hekouensis sp. nov.}

http://zoobank.org/1CEEDB31-AFF2-427B-A219-860D0C0C991E Figures 3-5

Type material. Holotype. KIZ20210510, adult male from Nanxi village, Nanxi Town, Hekou County, Honghe Prefecture, Yunnan Province, China $\left(22^{\circ} 38^{\prime} 17^{\prime \prime} \mathrm{N}\right.$, $103^{\circ} 59^{\prime} 8^{\prime \prime E}$, elevation $350 \mathrm{~m}$ a.s.1.), collected by Shuo Liu at 23:50 on 15 May 2021.

Paratype. KIZ20210511, adult female from the same locality as for the holotype, collected by Shuo Liu at 21:15 on 17 May 2021.

Diagnosis. Micryletta hekouensis sp. nov. can be distinguished from its congeners by a combination of the 
Table 2. Uncorrected p-distances (\%) of 16S rRNA sequences among Micryletta species and outgroups.

\begin{tabular}{|c|c|c|c|c|c|c|c|c|c|c|c|c|}
\hline & 1 & 2 & 3 & 4 & 5 & 6 & 7 & 8 & 9 & 10 & 11 & 12 \\
\hline \multicolumn{13}{|l|}{1 Micryletta aishani } \\
\hline 2 Micryletta dissimulans & 4.4 & & & & & & & & & & & \\
\hline 3 Micryletta erythropoda & 4.7 & 7.4 & & & & & & & & & & \\
\hline 4 Micryletta immaculata & 4.5 & 6.4 & 7.2 & & & & & & & & & \\
\hline 5 Micryletta inornata & 5.1 & 6.1 & 7.7 & 7.2 & & & & & & & & \\
\hline 6 Micryletta lineata & 3.2 & 6.0 & 2.9 & 9.5 & 6.5 & & & & & & & \\
\hline 7 Micryletta nigromaculata & 4.7 & 5.2 & 8.2 & 8.0 & 6.7 & 7.0 & & & & & & \\
\hline 8 Micryletta steinegeri & 3.5 & 4.8 & 6.6 & 4.2 & 5.6 & 5.1 & 7.1 & & & & & \\
\hline 9 Micryletta sumatrana & 5.9 & 5.1 & 9.1 & 8.3 & 8.2 & 7.4 & 5.5 & 6.0 & & & & \\
\hline 10 Micryletta hekouensis sp. nov. & 3.5 & 5.0 & 6.4 & 4.6 & 5.7 & 4.6 & 8.0 & 3.1 & 6.7 & & & \\
\hline 11 Mysticellus franki & 8.6 & 9.3 & 10.2 & 9.4 & 9.8 & 8.8 & 10.0 & 9.0 & 10.7 & 9.2 & & \\
\hline 12 Kaloula pulchra & 10.4 & 9.2 & 14.1 & 16.7 & 9.9 & 17.3 & 12.8 & 14.3 & 12.1 & 14.7 & 11.4 & \\
\hline 13 Uperodon systoma & 10.1 & 11.1 & 12.5 & 10.3 & 12.7 & 10.3 & 10.2 & 9.9 & 11.3 & 10.1 & 9.7 & 8.3 \\
\hline
\end{tabular}

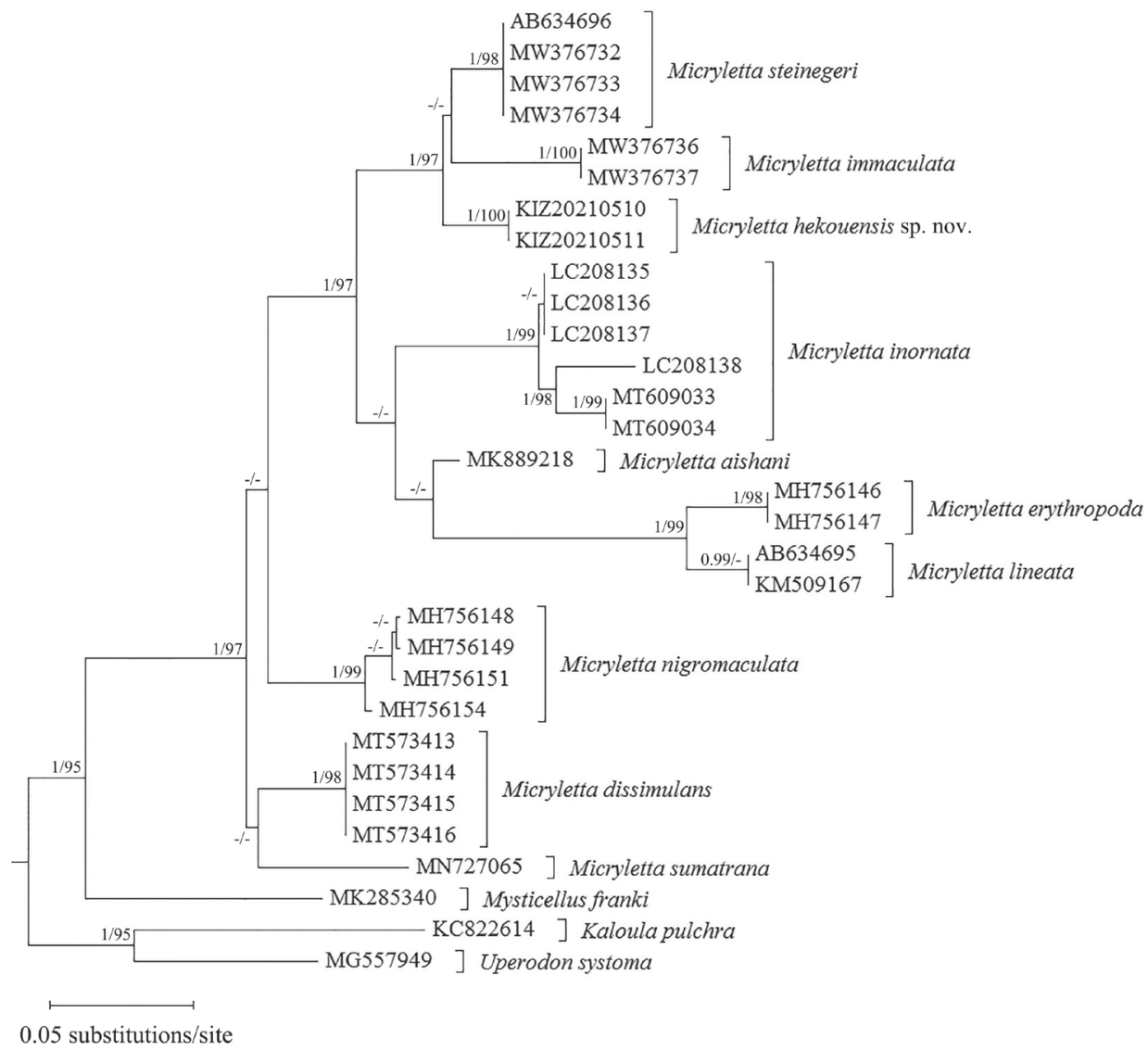

Figure 2. Bayesian Inference tree of Micryletta reconstructed on the base of $16 \mathrm{~S}$ rRNA gene sequences. Values before slashes correspond to Bayesian posterior probabilities ( $>0.9$ remain), and values after slashes correspond to Maximum Likelihood bootstrap replicates ( $>90$ remain).

following characters: small-sized within genus (SVL 20.5-20.8 mm); areas above canthus rostralis, upper eyelids, areas posterior to eyelids, and dorsum of upper arms golden, other parts of dorsum almost solid black or yellowish grey with brownish black stripes; lateral sides of head and body black or yellowish grey, a white stripe from lower front of eye along upper lip back to anterior forelimb insertion; ventral side of body and limbs pink brown, chin region in adult males brownish black, small and irregular white marbling patterns on chest and lateral belly; supratympanic fold indistinct; outer metatarsal tubercle absent; webbing between toes absent; tibiotarsal articulation adpressed limb reaching level of front of eye.

Description of holotype. Adult male. SVL $20.5 \mathrm{~mm}$; habitus relatively slender; head small and triangular, slightly wider (HW $6.9 \mathrm{~mm}$ ) than long (HL $6.5 \mathrm{~mm}$ ); snout (SL $2.9 \mathrm{~mm}$ ) abruptly rounded in dorsal view and slightly acuminate in profile, projecting beyond margin of lower jaw; eyes relatively small, slightly protuberant, pupil oval, transverse, eye diameter (EL $2.5 \mathrm{~mm}$ ) approximately equal to interorbital distance (IOD $2.4 \mathrm{~mm}$ ). Top of head flat, canthus rostralis rounded and distinct; loreal region weakly concave; nostril round, closer to tip 
A
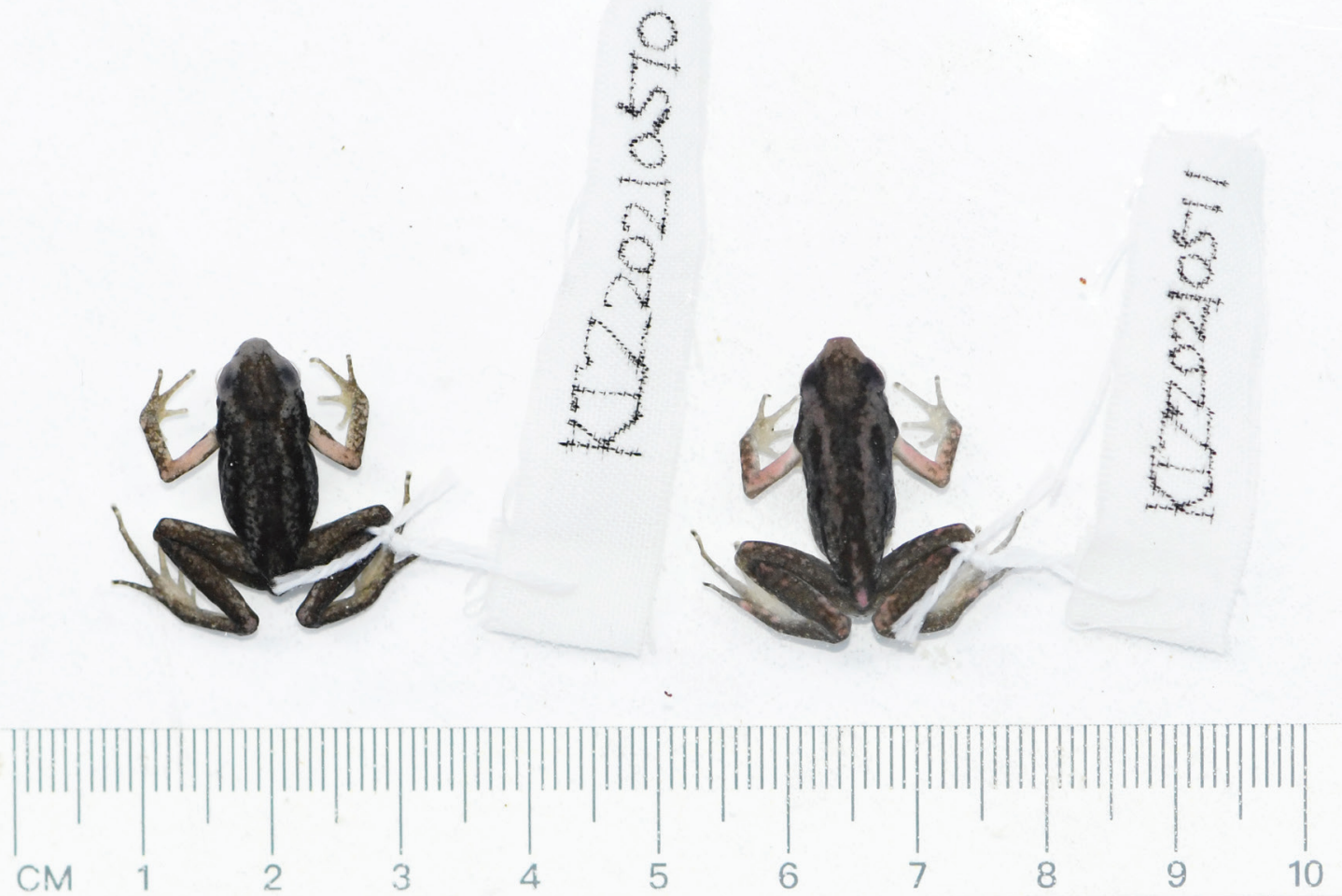

B
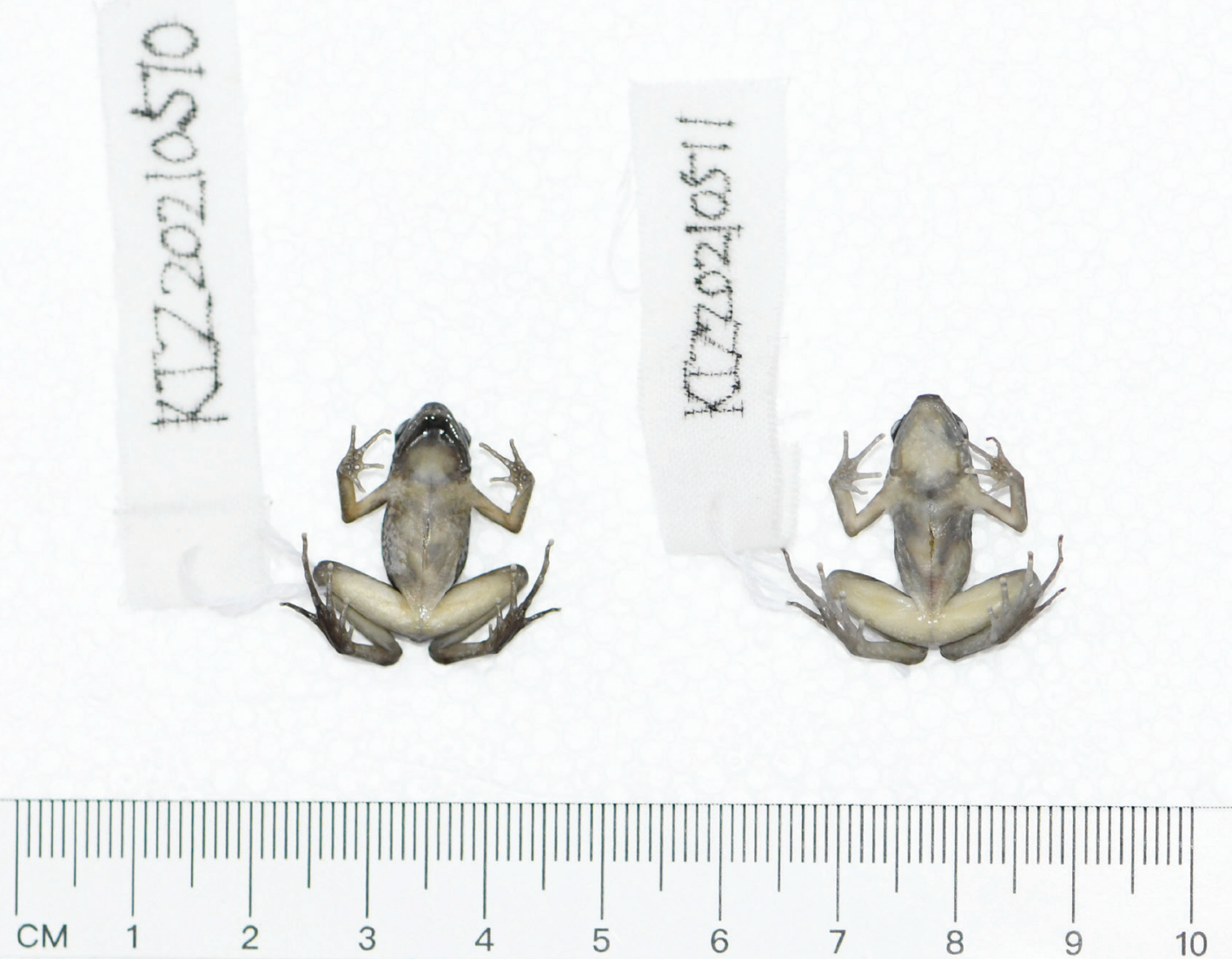

Figure 3. Type series of Micryletta hekouensis sp. nov. in preservative. A. dorsal view; B. ventral view. 


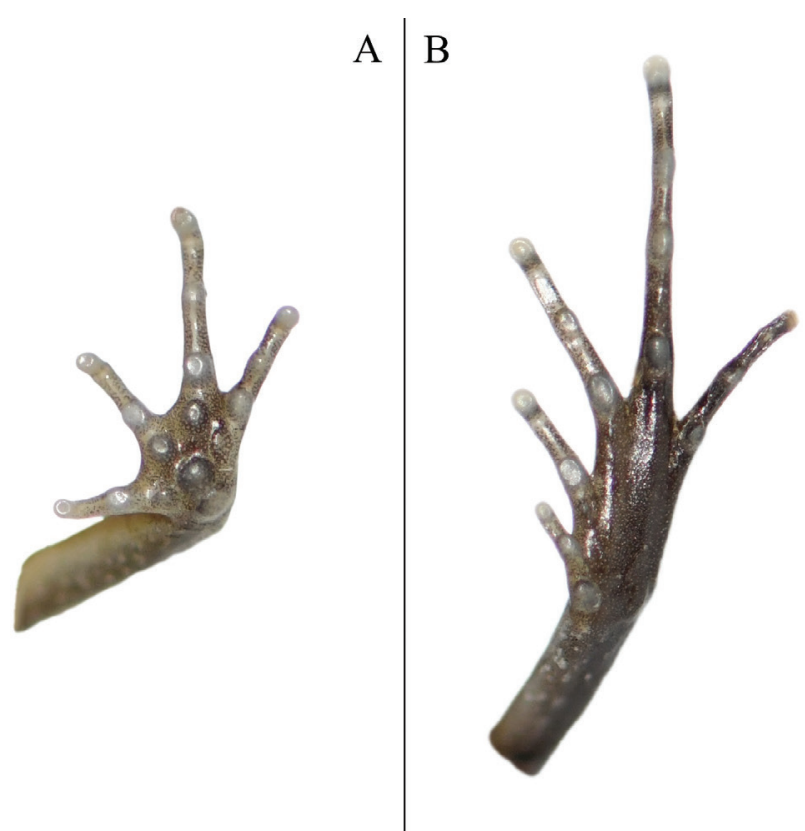

Figure 4. Close-up views of the hand and foot of the holotype (KIZ20210510) of Micryletta hekouensis sp. nov. A. volar view of left hand; B. plantar view of left foot.

of snout than to eye; interorbital distance (IOD $2.4 \mathrm{~mm}$ ) greater than internarial distance (IND $2.0 \mathrm{~mm}$ ) and upper eyelid width (UEW $1.7 \mathrm{~mm}$ ). Tympanum rounded, small (TMP $0.6 \mathrm{~mm}$ ) and distinct; supratympanic fold very indistinct. Choanae rounded; vomerine teeth absent; opening of vocal sac long cleft; tongue slender, with no notch at posterior tip.

Forelimbs slender (FLL $14.9 \mathrm{~mm}$ ), lower arm and hand length (LAL $10.9 \mathrm{~mm}$ ) more than a half of snoutvent length (LAL/SVL 0.53). Fingers slender with no webbing, rounded in cross-section, no lateral fringes; first finger well-developed, second finger slightly shorter than fourth, relative finger lengths: $\mathrm{I}<\mathrm{II}<\mathrm{IV}<\mathrm{III}$; tips of fingers round and not dilated; subarticular tubercles on fingers distinct, rounded and prominent, formula 1, 1, 2, 2; supernumerary tubercles on palm present and developed; three metacarpal tubercles, inner one rounded and smallest (IPTL $0.4 \mathrm{~mm}$ ), median one (MPTL $0.7 \mathrm{~mm}$ ) rounded and almost directly in front of elongated outer one (OPTL 0.8 $\mathrm{mm}$ ); two rounded and one elongated prominent supernumerary palmar tubercles on the base of fingers II-IV, respectively, slightly larger than inner metacarpal tubercle; nuptial pad absent.

Hindlimbs slender and long (HLL $33.3 \mathrm{~mm}$ ), more than two times longer than forelimbs (HLL/FLL 2.23); tibia (TL $10.9 \mathrm{~mm}$ ) slightly shorter than one-third of hindlimb length; tibiotarsal articulation of adpressed limb reaching level of front of eye; foot (FL $11.4 \mathrm{~mm}$ ) slightly longer than tibia. Relative toe lengths: $\mathrm{I}<\mathrm{II}<\mathrm{V}<\mathrm{III}<\mathrm{IV}$; tarsus smooth, tarsal fold absent; tips of toes round and not dilated, slightly wider than those of fingers; webbing between toes absent; subarticular tubercles on toes oval and prominent, formula: 1, 1, 2, 3, 2; dermal ridges present under $2^{\text {nd }}$ to $4^{\text {th }}$ toes but indistinct; inner metatarsal tu- bercle oval, prominent, and small (IMTL $0.7 \mathrm{~mm}$ ); outer metatarsal tubercle absent.

Dorsal skin smooth above, scattered with tiny and flat tubercles on dorsum of body, flanks, and hindlimbs; subtle longitudinal median ridge present on dorsum; dorsolateral fold absent; lateral sides of head smooth; ventral skin of body and limbs smooth.

Coloration of holotype in life. Areas above canthus rostralis, upper eyelids, areas just posterior to eyelids, dorsum of upper arms, and areas above tibiotarsal articulation golden; other parts of dorsum of body black with two indistinct parallel longitudinal grey stripes on back; other parts of dorsum of limbs black mottled with gray and yellow. Lateral sides of head and body black, from lower front of eye along upper lip back to anterior forelimb insertion white; one indistinct longitudinal grey stripe on each side of body. Ventral side of body and limbs pinkish brown, chin region brownish black; small and irregular white marbling patterns on chest and lateral belly; some small white spots on lower lip. Iris bicolored, with upper third bronze and lower two-thirds brownish black.

Coloration of holotype in preservative. Colors faded; areas above canthus rostralis, upper eyelids, and areas just posterior to eyelids turned to dark grey; dorsum of upper arms turned to pink; ventral side turned to yellowish white with light gray marbling on chest and lateral sides of belly; colors of other parts of body almost the same as in life.

Variation. The female paratype is quite similar in appearance to the holotype (Table 3), but show some variations in coloration. The female paratype has a relatively lighter body color, areas above canthus rostralis, upper eyelids, areas posterior to eyelids, and dorsum of upper arms are golden, the same as holotype; however, midline of the back is brownish black, one discontinuous black

Table 3. Measurements (in mm) of the type specimens of Micryletta hekouensis sp. nov.

\begin{tabular}{lccc}
\hline & KIZ20210510 & KIZ20210511 & Mean \pm SD (n=2) \\
\hline SVL & 20.5 & 20.8 & $20.65 \pm 0.21$ \\
HL & 6.5 & 7.3 & $6.90 \pm 0.57$ \\
SL & 2.9 & 2.8 & $2.85 \pm 0.07$ \\
EL & 2.5 & 2.4 & $2.45 \pm 0.07$ \\
NEL & 1.7 & 1.8 & $1.75 \pm 0.07$ \\
HW & 6.9 & 7.1 & $7.00 \pm 0.14$ \\
IND & 2.0 & 2.1 & $2.05 \pm 0.07$ \\
IOD & 2.4 & 2.2 & $2.30 \pm 0.14$ \\
UEW & 1.7 & 1.6 & $1.65 \pm 0.07$ \\
TMP & 0.6 & 0.7 & $0.65 \pm 0.07$ \\
FLL & 14.9 & 16.2 & $15.55 \pm 0.92$ \\
LAL & 10.9 & 11.6 & $11.25 \pm 0.49$ \\
HAL & 5.3 & 6.0 & $5.65 \pm 0.49$ \\
IFL & 3.1 & 3.1 & $3.10 \pm 0.00$ \\
IPTL & 0.4 & 0.4 & $0.40 \pm 0.00$ \\
MPTL & 0.7 & 0.7 & $0.70 \pm 0.00$ \\
OPTL & 0.8 & 0.8 & $0.80 \pm 0.00$ \\
3FDD & 0.5 & 0.4 & $0.45 \pm 0.07$ \\
HLL & 33.3 & 34.0 & $33.65 \pm 0.49$ \\
TL & 10.9 & 10.8 & $10.85 \pm 0.07$ \\
FL & 11.4 & 11.9 & $11.65 \pm 0.35$ \\
IMTL & 0.7 & 0.8 & $0.75 \pm 0.07$ \\
1TOEL & 2.6 & 3.1 & $2.85 \pm 0.35$ \\
4TDD & 0.6 & 0.5 & $0.55 \pm 0.07$ \\
\hline
\end{tabular}




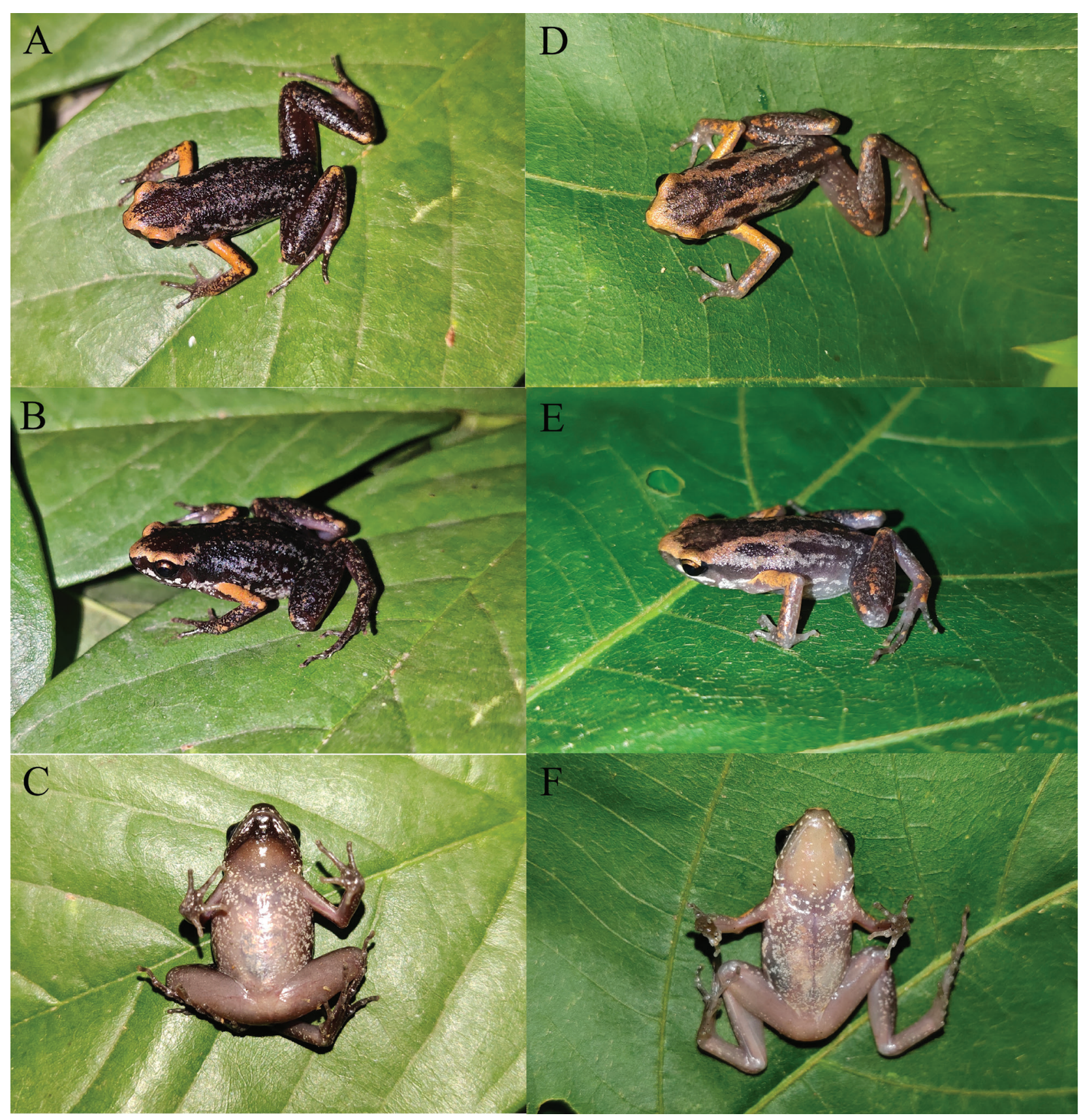

Figure 5. The holotype (KIZ20210510) and the paratype (KIZ20210511) of Micryletta hekouensis sp. nov. in life. A. dorsal view of the holotype; B. lateral view of the holotype; C. ventral view of the holotype; D. dorsal view of the paratype; E. lateral view of the paratype; F. ventral view of the paratype.

stripe dorsolateral on each side, lower parts of flanks greyish brown; other parts of dorsal and lateral body are yellowish grey; dorsa of lower arms and hindlimbs brownish grey with larger and more obvious irregular yellow spots. The color of the ventral side is similar to that of the holotype, except that the chin region is not brownish black but light yellow.

Sexual dimorphism. Male has opening of vocal sac and single hypopharyngeal vocal sac, female has no vocal sac and opening of vocal sac. Besides this, there is no significant morphological character difference between males and females.

Etymology. The specific epithet hekouensis refers to Hekou County, the type locality of the new species. We propose "Hekou Paddy Frog" for the common English name and “河口小姬蛙” (Hé Kǒu Xiăo Jī Wā) for the common Chinese name of the new species.

Natural history. Specimens of the new species were found in the grass on the ground at night. Once startled, they jumped away quickly. The collection site is surrounded by primary broad-leaved forest and bamboo. There are karst rocks nearby, no water body within a few hundred meters, and no courtship calls were heard. The collection site is in the nature reserve and the environment is not destroyed; this species is not threatened at present (Figure 6).

Distribution. This species is currently known only from the type locality, Nanxi Town, Hekou County, 


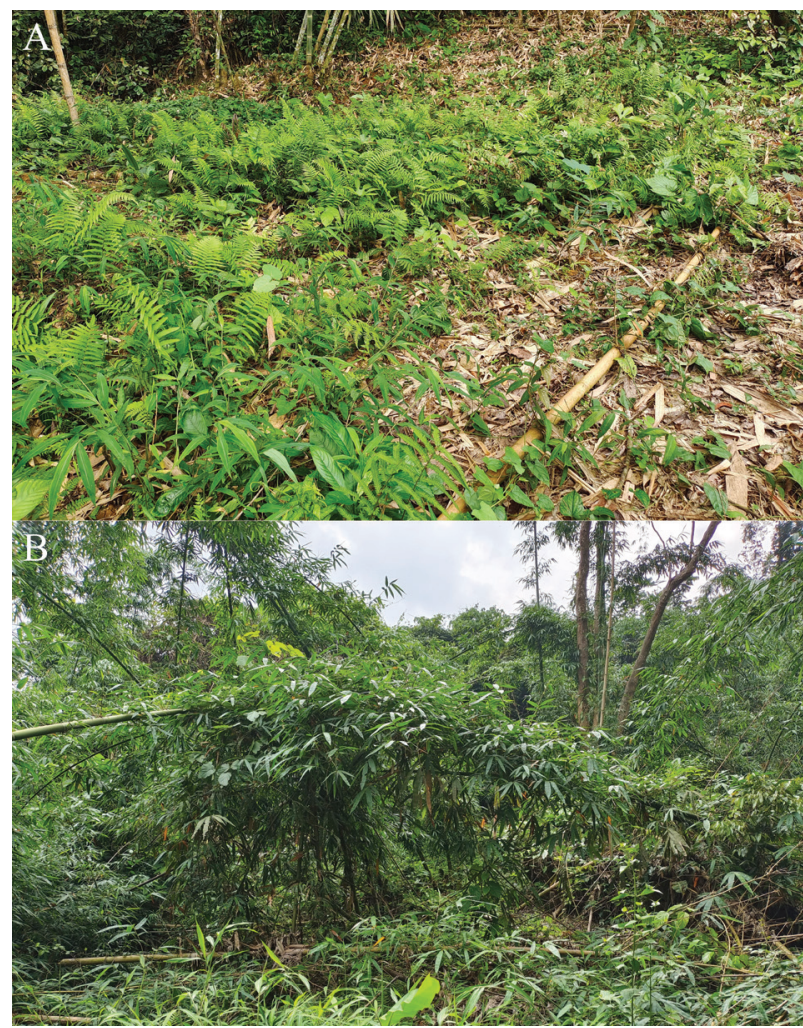

Figure 6. Habitat of Micryletta hekouensis sp. nov. at the type locality in Nanxi Town, Hekou County, Yunnan Province, China. A. The collection site; $\mathbf{B}$. The surroundings of the collection site.

Honghe Prefecture, Yunnan Province, China. It is expected to be found in neighboring Northern Vietnam.

Comparisons. Micryletta hekouensis sp. nov. differs from $M$. aishani by relatively smaller body size (SVL 20.5-20.8 mm vs. 22.1-27.3); snout abruptly rounded in dorsal view and slightly acuminate in lateral view (vs. snout shape nearly truncate in dorsal view and acute in lateral view); dorsum almost solid black or yellowish grey with brownish black stripes (vs. dorsum brown to reddish brown with several blackish brown spots present on posterior parts of back and near groin); tibiotarsal articulation adpressed limb reaching level of front of eye (vs. reaching to armpit).

Micryletta hekouensis sp. nov. differs from M. dissimulans by dorsum almost solid black or yellowish grey with brownish black stripes (vs. dorsum reddish brown with merging irregular shaped brown blotches edged in beige); flanks black or greyish brown (vs. large black spots on flanks and axillary and inguinal areas present); white stripes on upper lips present (vs. absent); tibiotarsal articulation adpressed limb reaching level of front of eye (vs. reaching to tympanum).

Micryletta hekouensis sp. nov. differs from M. erythropoda by relatively smaller body (SVL 20.5-20.8 mm vs. up to $30 \mathrm{~mm}$ ); dorsum almost solid black or yellowish grey with brownish black stripes (vs. dorsum gray or beige to saturated ochre or brick red, dark contrasting round or irregular shape spots irregularly scattered throughout the dorsum); venter without dark patterns (vs. with relatively distinct dark and light marbled speckling); outer metatarsal tubercle absent (vs. present); tibiotarsal articulation adpressed limb reaching level of front of eye (vs. reaching to posterior edge of tympanum).

Micryletta hekouensis sp. nov. can be distinguished from $M$. immaculata by relatively smaller body (SVL 20.5-20.8 mm vs. up to 23.3-30.1 mm); dorsum almost solid black or yellowish grey with brownish black stripes (vs. dorsum bronze brown to reddish brown without dark patterns); supratympanic fold indistinct (vs. distinct); supratympanic fold indistinct (vs. distinct); webbing between toes absent (vs. basal and poorly developed); tibiotarsal articulation adpressed limb reaching level of front of eye (vs. reaching to tympanum).

Micryletta hekouensis sp. nov. can be distinguished from $M$. inornata sensu stricto from Sumatra, Indonesia, and from Tanintharyi, Myanmar, by dorsum almost solid black or yellowish grey with brownish black stripes (vs. dorsum brownish grey with irregular blackish brown blotches and blackish brown streak); ventral side of body and limbs pinkish brown or pinkish grey with small and irregular white marbling patterns on chest and lateral belly (vs. ventral side of body and limbs light reddish grey without mottling, nearly immaculate, or chin, chest, and lateral belly with a few dark marbling patterns); tibiotarsal articulation adpressed limb reaching level of front of eye (vs. reaching to eye).

Micryletta hekouensis sp. nov. can be diagnosed from M. lineata by supratympanic fold indistinct (vs. distinct); venter pink brown with small and irregular white marbling patterns on chest and lateral belly (vs. venter beige with light brown mottling along throat); tibiotarsal articulation adpressed limb reaching level of front of eye (vs. reaching to eye).

Micryletta hekouensis sp. nov. differs from M. nigromaculata by supratympanic fold indistinct (vs. distinct); dorsum almost solid black or yellowish grey with brownish black stripes (vs. dorsum brown to reddish brown with dark brown irregular hourglass shaped pattern and two large dark inguinal spots); flanks black or greyish brown (vs. flanks greyish white with dark patches or spots); white stripes on upper lips present (vs. absent); chin region in males brownish black (vs. whitish with light-gray marbling); tibiotarsal articulation adpressed limb reaching level of front of eye (vs. reaching to eye).

Micryletta hekouensis sp. nov. differs from M. sumatrana by supratympanic fold indistinct (vs. distinct); dorsum almost solid black or yellowish grey with brownish black stripes (vs. dorsum golden brown scattered with black spots); dark cross bands on tibia and tarsus absent (vs. present); venter without dark patterns (vs. with dark brown and cream mottling).

Micryletta hekouensis sp. nov. differs from M. steinegeri by relatively smaller body (SVL 20.5-20.8 mm vs. up to $30 \mathrm{~mm}$ ); dorsum almost solid black or yellowish grey with brownish black stripes (vs. dorsum dark gray 
to violet with irregular dark blotches or speckles); venter without dark patterns (vs. with grayish white and brown spots); webbing between toes absent (vs. rudimentary webbing); tibiotarsal articulation adpressed limb reaching level of front of eye (vs. reaching to tympanum).

\section{Discussion}

Yang and Rao (2008), Fei et al. (2009), Fei et al. (2012), and AmphibiaChina (2021) all recorded Micryletta inornata distributed in Menglun Town, Mengla County, Xishuangbanna Prefecture, Yunnan Province, China. Micryletta inornata sensu lato was widely reported from mainland Southeast Asia; however, recent phylogenetic studies have indicated that $M$. inornata sensu stricto is restricted to Indonesia and southern Myanmar, and the populations of $M$. inornata sensu lato contain several undescribed paraphyletic lineages with respect to other named taxa (Das et al. 2019; Munir et al. 2020; Miller et al. 2021). Therefore, the population distribution in Xishuangbanna remains to be studied.

\section{Acknowledgements}

We would like to thank Decai Ouyang for assistance in the field. Thanks to our colleagues for their help and advice. We also thank the editors and reviewers for their work on the manuscript. This work was supported by Science-Technology Basic Condition Platform from the Ministry of Science and Technology of the People's Republic of China (Grant No. 2005DKA21402), and the project of Ministry of Ecology and Environment of China: Investigation and assessment of amphibians and reptiles in southern Yunnan.

\section{References}

Alhadi F, Hamidy A, Farajallah A, Munir M, Atmaja VY, Garg S, Biju SD, Smith EN (2019) Rediscovery of Micryletta inornata (Boulenger, 1890) from Sumatra: redescription, molecular identity and taxonomic implications. Zootaxa 4613(1): 111-126. https:/doi. org/10.11646/zootaxa.4613.1.5

AmphibiaChina (2021) The database of Chinese amphibians. Electronic Database. http://www.amphibiachina.org [Accessed on 1 June 2021]

Blackburn DC, Siler CD, Diesmos AC, McGuire JA, Cannatella DC, Brown RM (2013) An adaptive radiation of frogs in a Southeast Asian island archipelago. Evolution 67(9): 2631-2646. https://doi. org/10.1111/evo.12145

Boulenger GA (1890) List of the reptiles, batrachians, and freshwater fishes collected by Professor Moesch and Mr. Iversen in the district of Deli, Sumatra. Proceedings of the Zoological Society of London 1890: 30-39.

Boulenger GA (1909) Descriptions of four new frogs and a new snake discovered by Mr. H. Sauter in Formosa. Annals and Mag- azine of Natural History Series 4(24): 492-495. https://doi. org/10.1080/00222930908692704

Das A, Garg S, Hamidy A, Smith EN, Biju SD (2019) A new species of Micryletta frog (Microhylidae) from Northeast India. PeerJ 7: e7012. https://doi.org/10.7717/peerj.7012

De Sá RO, Streicher JW, Sekonyela R, Forlani MC, Loader SP, Greenbaum E, Richards S, Haddad CFB (2012) Molecular phylogeny of microhylid frogs (Anura: Microhylidae) with emphasis on relationships among New World genera. BMC Evolutionary Biology 12: e241. https://doi.org/10.1186/1471-2148-12-241

Dubois A (1987) Miscellanea taxinomica batrachologica, II. Alytes 6: $1-9$.

Fei L (1999) Atlas of Amphibians of China. Henan Press of Science and Technology, Zhengzhou, $432 \mathrm{pp}$.

Fei L, Hu SQ, Ye CY, Huang YZ (2009) Fauna Sinica (Vol. 2). Amphibia Anura. Science Press, Beijing, 957 pp.

Fei L, Ye CY, Jiang JP (2012) Colored Atlas of Chinese Amphibians and Their Distributions. Sichuan Publishing House of Science and Technology, Chengdu, 620 pp.

Frost DR, Grant T, Faivovich J, Bain RH, Haas A, Haddad CFB, De Sá RO, Channing A, Wilkinson M, Donnellan SC, Raxworthy CJ, Campbell JA, Blotto BL, Moler P, Drewes RC, Nussbaum RA, Lynch JD, Green DM, Wheeler WC (2006) The amphibian tree of life. Bulletin of the American Museum of Natural History 297: 1-291. https://doi. org/10.1206/0003-0090(2006)297[0001:TATOL]2.0.CO;2

Garg S, Biju SD (2019) New microhylid frog genus from Peninsular India with Southeast Asian affinity suggests multiple Cenozoic biotic exchanges between India and Eurasia. Scientific Reports 9(1): e1906. https://doi.org/10.1038/s41598-018-38133-x

Hedges SB (1994) Molecular evidence for the origin of birds. Proceedings of the National Academy of Sciences of the United States of America 91(7): 2621-2624. https://doi.org/10.1073/pnas.91.7.2621

Hillis DM, Moritz C, Mable BK (1996) Molecular Systematics ( $2^{\text {nd }}$ Edn.). Sinauer Associates, Sunderland, 655 pp. https://doi. org/10.2307/1447682

Huelsenbeck JP, Ronquist F, Nielsen R, Bollback JP (2001) Bayesian inference of phylogeny and its impact on evolutionary biology. Science 294(5550): 2310-2314. https://doi.org/10.1126/science.1065889

Kalyaanamoorthy S, Minh BQ, Wong TKF, von Haeseler A, Jermiin LS (2017) ModelFinder: fast model selection for accurate phylogenetic estimates. Nature Methods 14: 587-589. https://doi.org/10.1038/ nmeth. 4285

Kumar S, Stecher G, Li M, Knyaz C, Tamura K (2018) MEGA X: Molecular Evolutionary Genetics Analysis across computing platforms. Molecular Biology and Evolution 35: 1547-1549. https://doi. org/10.1093/molbev/msy096

Kurabayashi A, Matsui M, Belabut DM, Yong H, Ahmad N, Sudin A, Kuramoto M, Hamidy H, Sumida M (2011) From Antarctica or Asia? New colonization scenario for Australian-New Guinean narrow mouth toads suggested from the findings on a mysterious genus Gastrophrynoides. BMC Evolutionary Biology 11(1): e175. https:// doi.org/10.1186/1471-2148-11-175

Matsui M, Shimada T, Liu W-Z, Maryati M, Khonsue W, Orlov N (2006) Phylogenetic relationships of Oriental torrent frogs in the genus Amolops and its allies (Amphibia, Anura, Ranidae). Molecular Phylogenetics and Evolution 38(3): 659-666. https://doi. org/10.1016/j.ympev.2005.11.019 
Miller AH, Zug GR, Wogan GOU, Lee JL, Mulcahy DG (2021) Phylogeny, diversity, and distribution of Micryletta (Anura: Microhylidae) in Myanmar. Ichthyology \& Herpetology 109(1): 245-257. https:// doi.org/10.1643/h2020100

Minh Q, Nguyen MAT, von Haeseler A (2013) Ultrafast approximation for phylogenetic bootstrap. Molecular Biology and Evolution 30(5): 1188-1195. https://doi.org/10.1093/molbev/mst024

Munir M, Hamidy A, Matsui M, Kusrini MD, Nishikawa K (2020) A new species of Micryletta (Amphibia: Anura) from Sumatra, Indonesia. Zoological Science 37(3): 295-301. https://doi.org/10.2108/ zs200006

Nguyen LT, Schmidt HA, von Haeseler A, Minh BQ (2015) IQ-TREE: a fast and effective stochastic algorithm for estimating maximum-likelihood phylogenies. Molecular Biology and Evolution 32: 268-274. https://doi.org/10.1093/molbev/msu300

Peloso PLV, Frost DR, Richards SJ, Rodrigues MT, Donnellan S, Matsui M, Raxworthy CJ, Biju SD, Lemmon EM, Lemmon AR, Wheeler WC (2016) The impact of anchored phylogenomics and taxon sampling on phylogenetic inference in narrow-mouthed frogs (Anura, Microhylidae). Cladistics 32(2): 113-140. https://doi.org/10.1111/ cla. 12118

Poyarkov NA, Nguyen TV, Duong TV, Gorin VA, Yang JH (2018) A new limestone-dwelling species of Micryletta (Amphibia: Anura: Microhylidae) from northern Vietnam. PeerJ 6: e5771. https://doi. org/10.7717/peerj.5771

Pyron RA, Wiens JJ (2011) A large-scale phylogeny of Amphibia including over 2800 species, and a revised classification of extant frogs, salamanders, and caecilians. Molecular Phylogenetics and Evolution 61(2): 543-583. https://doi.org/10.1016/j. ympev.2011.06.012

Ronquist F, Teslenko M, Van Der Mark P, Ayres DL, Darling A, Höhna S, Larget B, Liu L, Suchard MA, Huelsenbeck JP (2012) MrBayes 3.2: efficient Bayesian phylogenetic inference and model choice across a large model space. Systematic Biology 61: 539-542. https://doi.org/10.1093/sysbio/sys029

Sambrook JF, Russell RW (2001) Molecular Cloning: A Laboratory Manual. Third Edition. Cold Spring Harbor Laboratory Press, New York, $2345 \mathrm{pp}$.

Suwannapoom C, Nguyen TV, Pawangkhanant P, Gorin VA, Chomdej S, Che J, Poyarkov NA (2020) A new species of Micryletta (Amphibia:
Microhylidae) from southern Thailand. Zoological Research 41(5): 581-588. https://doi.org/10.24272/j.issn.2095-8137.2020.139

Tarkhnishvili DN (1994) Amphibian communities of the southern Viet Nam: preliminary data. Journal of the Bengal Natural History Society $13(1): 3-62$.

Taylor EH (1962) The amphibian fauna of Thailand. University of Kansas Science Bulletin 43: 265-599. https://www.biodiversitylibrary. org/page/4379553

Thompson JD, Higgins DG, Gibson TJ (1994) CLUSTAL W: improving the sensitivity of progressive multiple sequence alignment through sequence weighting, position-specific gap penalties and weight matrix choice. Nucleic Acids Research 22: 4673-4680. https://doi. org/10.1093/nar/22.22.4673

Tu N, Yang MH, Liang D, Zhang P (2018) A large-scale phylogeny of Microhylidae inferred from a combined dataset of 121 genes and 427 taxa. Molecular Phylogenetics and Evolution 126: 85-91. https://doi.org/10.1016/j.ympev.2018.03.036

Van der Meijden A, Vences M, Hoegg S, Boistel R, Channin GA, Meyer A (2007) Nuclear gene phylogeny of narrow-mouthed toads (Family: Microhylidae) and a discussion of competing hypotheses concerning their biogeographical origins. Molecular Phylogenetics and Evolution 44(3): 1017-1030. https://doi.org/10.1016/j. ympev.2007.02.008

Wilcox TP, Zwickl DJ, Heath TA, Hillis DM (2002) Phylogenetic relationships of the Dwarf Boas and a comparison of Bayesian and bootstrap measures of phylogenetic support. Molecular Phylogenetics and Evolution 25: 361-371. https://doi.org/10.1016/S10557903(02)00244-0

Yang DT, Rao DQ (2008) Amphibia and Reptilia of Yunnan. Yunnan Publishing Group Corporation, Yunnan Science and Technology Press, Kunming, 411 pp.

Yang JH, Poyarkov NA (2021) A new species of the genus Micryletta (Anura, Microhylidae) from Hainan Island, China. Zoological Research 42(2): 234-240. https://doi.org/10.24272/j.issn.20958137.2020 .333

Zhao EM, Adler K. 1993. Herpetology of China. Society for the Study of Amphibians and Reptiles, Oxford, 552 pp.

Zug GR, Mulcahy DG (2020) Identification Guide - Amphibians \& Reptiles of South Tanintharyi. Fauna \& Flora International, Cambridge, 203 pp. 